\title{
Narrativas alegóricas: do Barroco à contemporaneidade
}

\author{
Vivian Bernardes Margutti \\ Doutora em Literatura Comparada / UFMG
}

\begin{abstract}
RESUMO
Investiga-se o caráter alegórico do romance contemporâneo No país das últimas coisas, através de suas ligações intertextuais com a paródia “A estrada de ferro celestial”, e a alegoria intitulada O peregrino. A partir de tal leitura, analisam-se também as relações entre a alegoria e o surgimento do romance.
\end{abstract}

\section{PALAVRAS-CHAVE}

Literatura de língua inglesa, alegoria, romance, Walter Benjamin, Literatura contemporânea

\section{INTRODUÇÃO}

A alegoria, como recurso retórico e como gênero textual, tem sido utilizada na tradição literária desde a época Medieval. Um dos exemplos mais significativos é a Divina Comédia de Dante Alighieri, que trabalha com temas religiosos em um mundo imaginário criado através da linguagem da ficção. Nesta longa tradição, a alegoria se adaptou de forma flexível aos mais diversos cenários históricos, sempre estabelecendo laços com questões de cunho teológico.

Este estudo relaciona três obras de épocas diferentes, nas quais a alegoria tem papel predominante: o romance contemporâneo No país das últimas coisas (1987), de Paul Auster (1947-), a paródia romântica “A estrada de ferro celestial” (1843), de Nathaniel Hawthorne (1804-1864) e a alegoria barroca O peregrino (1678), de John Bunyan (1628-1688). Tal relação é sugerida na epígrafe de No país das últimas coisas e demonstra que, apesar de associada ao gênero do romance, a narrativa de Auster apresenta características que a aproximam de uma configuração contemporânea da alegoria. Ao levar em consideração as ligações entre a alegoria, o surgimento do romance e a forma como ambos os gêneros 
mantiveram um diálogo ao longo da tradição literária, propõe-se que o texto escrito por Auster seja um romance alegórico.

\section{A ALEGORIA}

No livro Alegoria: construção e interpretação da metáfora, o professor Adolfo Hansen descreve o trajeto dessa figura desde a Antiguidade. ${ }^{1}$ Esse livro será utilizado como um apoio para introduzir as diversas configurações da alegoria no percurso histórico até o Renascimento. No Período Barroco adota-se a noção de alegoria descrita em Origem do drama barroco alemão pelo teórico Walter Benjamin. ${ }^{2}$ Posteriormente, é feito um esboço das ideias do crítico literário desconstrutivista, Paul de Man, ${ }^{3}$ que discute o preconceito romântico com relação ao uso da alegoria em contraposição ao símbolo no século 19.

A palavra alegoria vem do grego e significa dizer uma coisa para significar outra (állos = outro; agorein $=$ falar). Hansen destaca dois tipos de alegoria que se contrapõem e se complementam simultaneamente: a alegoria dos poetas e a alegoria dos teólogos. A primeira se caracteriza por ser uma forma de “expressão verbal retórico-poética”, bastante utilizada na Antiguidade para ornamentar discursos que se oferecem à interpretação. Sua técnica engloba a utilização de um locus ou lugar-comum e um vocabulário que substituem determinado discurso de forma figurada.

A segunda alegoria é hermenêutica, pois pressupõe uma "interpretação religiosa de coisas, homens e eventos figurados em textos sagrados”. Em contraposição à visão grecoromana da Antiguidade, a alegoria dos teólogos é cristã e medieval, de forma que seus pressupostos são essencialistas, considerando Deus a origem de todas as coisas.

A interpretação alegórica da Bíblia prevalece durante séculos. Filo de Alexandria (2025 a.C) é o precursor desse método de exegese, que domina durante toda a Idade Média. Nessa época, é criada a “quadriga” para distinguir os quatro sentidos das Escrituras: o histórico, o alegórico, o tropológico e o anagógico. Segundo Lopes, na Idade Média o método alegórico de interpretação bíblica é utilizado de forma distorcida para justificar as inovações, os costumes e as doutrinas que surgem na Igreja. ${ }^{4}$

\footnotetext{
${ }^{1}$ Cf. HANSEN. Alegoria: construção e interpretação da metáfora.

${ }^{2}$ Cf. BENJAMIN. Origem do drama barroco alemão.

${ }^{3}$ Cf. DE MAN. Alegorias da leitura: linguagem figurativa em Rousseau, Nietzsche, Rilke e Proust.

${ }^{4}$ LOPES. Uma breve história da interpretação, p. 83-96 e 149-150.
} 
Dante Alighieri escreve sobre a alegoria na Carta XIII dirigida ao Can Grande della Scala, seu patrono e protetor. Segundo Holloway, a carta inclui a interpretação histórica (literal), alegórica, moral e anagógica do Salmo 113, que é considerado a matriz da Divina Comédia. Holloway afirma que a Divina Comédia seria uma tipologia do salmo 113, que, por sua vez, é uma tipologia do livro do Êxodo. A partir da ideia cristã medieval de que a Bíblia relata fatos reais com implicações espirituais, a obra de Dante pode ser interpretada simultaneamente como fato (alegoria dos teólogos) e ficção (alegoria dos poetas).5 Dante foi inovador ao mesclar os dois tipos de alegoria. Além disso, reforçou a tradição medieval cristã, que, apesar de considerar que a alegoria tem vários sentidos (polysemous), aponta para uma única crença espiritual. Dessa forma, o resultado interpretativo acaba sendo algo definido e, portanto, unívoco.

No Renascimento, de acordo com o estudo de Hansen, destaca-se o interesse em traduzir e interpretar os textos filosóficos e poéticos gregos e latinos. Instrumentos como os hieróglifos egípcios, a astrologia, a alquimia e a Cabala passam a ser utilizados com tal intuito, e a alegoria se torna “o instrumento principal de interpretação e construção dos discursos”. ${ }^{6}$ Entretanto, ao contrário da alegoria medieval, perdem-se não apenas a ideia de uma retórica que leva à "tradução figurada de um sentido próprio", 7 mas também as referências unicamente cristãs, trazendo uma abertura eclética para a busca de um sentido inefável. A arte, a alegoria e o além se misturam de uma forma ampla, incluindo crenças, religiões, os deuses gregos, a escrita dos antigos egípcios, conhecimentos de astrologia, o pensamento platônico e a matemática, entre outros. Assim, a alegoria se torna plurívoca, sem deixar de lado uma determinada lógica interpretativa.

Em Origem do drama barroco alemão, Walter Benjamin traz à tona uma visão diferenciada da alegoria do Período Barroco, abrindo as portas para a percepção de um mundo incompleto e fragmentado, no qual todos caminham naturalmente para a fatalidade da morte. Segundo Benjamin, esse sentimento se faz presente devido à Reforma Protestante e, posteriormente, à Contrarreforma Católica, movimentos que quebraram paradigmas, resultando, contraditoriamente, em uma percepção da história esvaziada de qualquer tipo de transcendência e, também, de escatologia. Enquanto na Idade Média a história se inseria no

\footnotetext{
${ }^{5}$ HOLLOWAY. The pilgrim and the book: a study of Dante, Langland, and Chaucer, p. 165.

${ }^{6}$ HANSEN. Alegoria: construção e interpretação da metáfora, p. 140.

${ }^{7}$ HANSEN. Alegoria: construção e interpretação da metáfora, p. 140.
} 
processo da salvação, no Barroco a história se transforma em uma sequência de catástrofes, seguida da aniquilação final. A vida humana passa a ser sujeita ao destino e ao efêmero.

Ao analisar o drama barroco, Benjamin declara que a alegoria é uma linguagem que se adapta ao pensamento da época, pois retrata em sua forma e em seu conteúdo a ambiguidade de sentido, a incompletude, a morte e a decadência, tão presentes na percepção barroca.

\footnotetext{
Quando, com o drama barroco, a história penetra no palco, ela o faz enquanto escrita. A palavra história está gravada, com os caracteres da transitoriedade, no rosto da natureza. A fisionomia alegórica da naturezahistória, posta no palco pelo drama, só está verdadeiramente presente como ruína. ${ }^{8}$
}

Benjamin dá destaque à visão de um mundo histórico em estilhaços, e que se torna enigmático aos olhos daquele que o experimenta. Há, portanto, uma espécie de busca de decifração através de uma linguagem alegórica que faz agrupamentos de determinados fragmentos, com o intuito de compreendê-los: "é sob a forma de fragmentos que as coisas olham o mundo, através da estrutura alegórica." ${ }^{9}$ Tal estrutura pode ser representada pela retirada de um dado objeto de seu contexto, trazendo o consequente esvaziamento de sua significação e, posteriormente, pela transferência desse objeto a um novo e diferente contexto. Dessa forma, a concepção de história se estilhaça, mas o objeto se renova ao renascer com uma nova significação.

É interessante destacar que a leitura de Benjamin engloba tanto o objeto artístico como o pensamento presente na época, de forma que ambos estejam em sintonia com a concepção de alegoria. No Romantismo, o símbolo é exaltado em detrimento da alegoria, já que essa última é considerada deficiente, por ser processual e progressiva, não podendo incorporar em si, como o símbolo o faz, a clareza e a graça do momento místico. De forma semelhante, a crítica romântica traz à tona pressupostos relacionados à concepção da arte e ao pensamento da época, que buscam refletir uma ideia imediata de totalidade e transcendência. Tais pressupostos são ressaltados por Paul de Man em The rhetoric of temporality.

De Man dá destaque às ambiguidades presentes no pensamento romântico, ao considerar a superioridade do símbolo como um elemento que possui uma unidade orgânica, e a inferioridade da alegoria como uma forma imaterial que representa fantasmas sem substância. Além dessa contraposição não ser exata, De Man aponta a deficiência do símbolo em abranger a temporalidade, como acontece com a alegoria. O símbolo se refere a um

\footnotetext{
${ }^{8}$ BENJAMIN. Origem do drama barroco alemão, p. 199.

${ }^{9}$ BENJAMIN. Origem do drama barroco alemão, p. 208.
} 
momento místico, já a alegoria, por ser processual, apresenta uma continuidade no tempo e no espaço. Um exemplo seria a alegoria de Dante, que narra uma história que tem progressividade e temporalidade.

Em contraposição, o símbolo não faz referência ao ciclo da vida, no qual se insere a inevitabilidade do envelhecimento e da morte. Segundo De Man, o esplendor do símbolo funciona como uma espécie de véu que esconde tal inevitabilidade. A intenção da utilização exclusiva do símbolo, durante o Romantismo, aponta para uma busca pelo transcendente. Entretanto, mesmo tendo criticado a alegoria, muitos autores românticos, como Poe, Hawthorne, Rousseau e Wordsworth, utilizaram-na em suas obras.

As críticas dos autores românticos à alegoria, apesar das incongruências nelas encontradas, tiveram algum sucesso na rejeição da mesma. Devido a isso, desde esse período a analogia tem sido utilizada de uma forma mais discreta e sutil. O trabalho de Walter Benjamin foi de grande importância, no entanto, para desmistificar pensamentos discriminatórios, tanto relativos à alegoria como ao Período Barroco. Hansen destaca a maneira pela qual Benjamin identifica nas litanias satânicas da poesia modernista de Baudelaire um teor alegórico, que permite que sejam interpretadas como o outro da história, ou seja, como sendo a favor dos proletários, demonizados pela classe dominante. ${ }^{10}$ No livro de Paul de Man, Alegorias da leitura, escritores da Modernidade, como Nietzsche, Rilke e Proust, são também lidos de forma alegórica. ${ }^{11}$

A partir do pensamento de Benjamin e da intertextualidade presente em Auster, afirma-se que a alegoria tem sido utilizada desde o Período Barroco até a atualidade seguindo um padrão semelhante. Houve uma suposta ruptura com a sua utilização no período do Romantismo. Entretanto, a figura de linguagem foi retomada no Modernismo.

É importante ressaltar que muitas das características barrocas da alegoria permanecem na atualidade. O mundo contemporâneo apresenta traços que foram herdados do Período Barroco, como a transitoriedade, a incompletude, a ambiguidade de sentido e a morte. Tendo como base a leitura de No país das últimas coisas, percebe-se que o alegorista do século 20 também se debruça, com seu olhar melancólico, sobre os cacos da história em busca de algum tipo de decifração. Entretanto, após selecionar os objetos que serão alocados em um novo contexto, sua releitura é menos caricatural e mais realista do que aquela feita pelo alegorista barroco.

\footnotetext{
${ }^{10}$ HANSEN. Alegoria: construção e interpretação da metáfora p. 18.

${ }^{11}$ DE MAN. Alegorias da leitura: linguagem figurativa em Rousseau, Nietzsche, Rilke e Proust.
} 


\section{A ALEGORIA ROMÂNTICA E A CONTEMPORÂNEA}

Com o intuito de compreender o diálogo que se dá entre a alegoria contemporânea de Auster e a alegoria romântica de Hawthorne é interessante destacar as relações entre o âmbito da estética e o campo da economia. Considera-se para esta pesquisa a análise de Weinstein, especialista em literatura e cultura do século 19, que relaciona a representação do trabalho em textos ficcionais e não ficcionais, fazendo interseções com os campos da estética e da economia.

Segundo Weinstein, a alegoria passou por uma reconfiguração no contexto do industrialismo. Ao mesmo tempo que a alegoria do século 19 faz alusão à alegoria religiosa utilizada pelo reformista protestante John Bunyan, dela se distingue por trazer à tona questões relacionadas ao trabalho e à identidade pessoal. O estudo de Weinstein analisa o período da história dos EUA que engloba os anos de 1789 a 1849, conhecido como Antebellum era.

De acordo com Weinstein, esse período trouxe alterações no âmbito da relação do indivíduo com o trabalho devido ao grande e rápido progresso na área da indústria. O ritmo mecânico, repetitivo e exaustivo era pesado para o corpo humano, gerando consequências negativas para a saúde do operário. Esse resultado entrava em conflito com a ética do trabalho vigente nos EUA, que prometia a prosperidade e a possibilidade de crescimento a todos que fossem diligentes.

Apesar da ideia de classe social não fazer parte de tal ética, a sociedade americana se tornava cada vez mais segregadora. Enquanto alguns trabalhavam em condições ruins, outros permaneciam no ócio. Devido à estratificação social gerada, Weinstein explica que o trabalho começava, também, a afetar o indivíduo no nível da construção de sua identidade pessoal. Assim, com o intuito de camuflar o contexto ao redor da ética do trabalho e suas reais consequências, procurou-se apagar qualquer sinal que trouxesse para a cena a visibilidade do trabalho. "At the very moment that the ideological foundations of the work ethic were being called into question by new conditions of labor, the best guarantee of a salutary work ethic was the invisibility of work itself.”12

Segundo Weinstein, a alegoria e o trabalho mecanizado são criticados nesse período, pois, além de revelar o esforço do operário ou do escritor, podem produzir um tipo de indivíduo superficial. Tal afirmação é percebida através de sua análise sua do personagem “John A. B. C. Smith”, do conto de Poe “The man that was used up”. O personagem alegórico

\footnotetext{
${ }^{12}$ WEINSTEIN. The literature of labor and the labors of literature: allegory in nineteenth-century American fiction, p. 23.
} 
é um homem com movimentos mecânicos devido a seus braços e pernas artificiais. Ele é um produto do trabalho em uma economia de mercado, que utiliza formas compensatórias para corrigir seus erros. Os membros artificiais, criados pelo mercado, oferecem de volta ao personagem aquilo que o próprio mercado lhe havia tirado.

A pesquisa de Weinsten tem grande pertinência e perspicácia, pois relaciona dois âmbitos aparentemente distintos, mas que tendem a se encontrar em um nível ideológico: a alegoria e a economia. Nota-se também a continuidade com Benjamin, que insere a alegoria no contexto histórico, evidenciando um diálogo entre os dois. Na maioria das vezes, observase o surgimento de uma literatura engajada com um determinado pensamento de cunho social.

Weinstein analisa também “A estrada de ferro celestial”, de Nathaniel Hawthorne, no qual as marcas do trabalho parecem estar no âmbito da invisibilidade. Entretanto, o mero fato de Hawthorne estar parodiando já sugere a imagem de um escritor que trabalha relendo e reescrevendo. A ferrovia denota o período do industrialismo e a alegoria de Hawthorne ironiza a ideia da comodidade, além de ressaltar algumas características do mercado da troca e do acúmulo. Destaca-se, na paródia, o uso de nomes alegóricos que sugerem personagens de caráter questionável, os quais seriam figuras da impostura.

A interseção entre alegoria e ironia observada no texto de Hawthorne aponta em duas direções: a da continuidade de uma tradição alegórica e, simultaneamente, a de uma retórica da ironia, seguindo os passos já iniciados por Cervantes com Dom Quixote. Este estudo sugere, a partir da leitura de Benjamin, uma configuração contemporânea da alegoria, figura que foi silenciada no Romantismo por motivos éticos e estéticos, embora tenha sido utilizada por vários autores românticos. Na modernidade, o preconceito dos românticos parece ter permanecido. A referida figura de linguagem é associada, na maior parte dos casos, a obras de tempos e pensamentos remotos.

Afirma-se que No país das últimas coisas, escrito no período de 15 anos entre 1970 e 1985, ${ }^{13}$ é um romance contemporâneo que faz uso de recursos alegóricos. Levando em consideração o pensamento de Benjamin, propõe-se que a retórica de Auster se estruture mais especificamente a partir da história dos EUA. Destacam-se os momentos iniciais dessa história com a vinda dos europeus para a América. Posteriormente, nasce a sociedade industrial e seus ideais de progresso e liberalismo.

A obra No país das últimas coisas foi escrita no fim da Guerra Fria, em um mundo que enfatizava o consumismo e os velozes avanços tecnológicos. O cenário do romance aponta

\footnotetext{
${ }^{13}$ AUSTER. In the country of last things, p. 292.
} 
para o fantasma do Holocausto, as Guerras Mundiais e os ataques nucleares em Hiroshima e Nagasaki. A prosa alegórica de Auster deixa transparecer algumas consequências perversas da história do século 20 e do capitalismo moderno, como o crescimento desordenado do extrativismo natural e mineral, com o único objetivo de gerar lucro financeiro. É criado, então, um desequilíbrio com o meio ambiente, afetando a sustentabilidade do planeta.

A retórica de Auster, além de fazer referência a críticas sociais através da utilização da alegoria, traz à tona também um discurso irônico que é próprio da modernidade e do romance. Neste artigo defende-se que No país das últimas coisas apresenta uma mescla de características, constituindo o que será considerado um romance alegórico. Com o intuito de compreender melhor o encontro entre o gênero do romance e a figura da alegoria, será feita uma análise sobre a evolução do romance a partir dos escritos de Walter Benjamin e Georg Luckács.

\section{A ALEGORia E O ROMANCE}

Com relação à origem do romance há duas linhas diferentes entre os teóricos da literatura: a primeira considera que o romance pertence ao gênero épico ou narrativo, assim como o conto, a crônica, o mito e a epopeia. As duas últimas seriam as espécies mais remotas do gênero. O mito tem caráter sagrado e se baseia na memória do princípio, contando a história do começo de todas as coisas. A epopeia narra a história de um determinado povo, permeada pela ação de deuses e entes sobrenaturais. Sua forma obedece a certas convenções formais, e seu enredo se baseia em relatos bíblicos, lendários ou históricos, sempre voltados para a tradição coletiva e para a noção de que tais relatos constituem "um repertório definitivo da experiência humana”. ${ }^{14}$

A segunda linha de pensamento está vinculada aos estudos do teórico russo Mikhail Bakhtin, que discorda da filiação do romance ao gênero épico, propondo que ele constitua um gênero próprio denominado romanesco. Bakhtin descreve a epopeia como um poema sobre o passado e como um gênero acabado, diferenciando-a assim do romance, que é um gênero inacabado e que tem como objeto o presente e a atualidade. O estudo demonstra, a partir de características estruturais e temáticas de autores e textos da tradição ocidental, o distanciamento entre os dois gêneros.

Em “O narrador”, seguindo a primeira linha de pensamento exposta acima, Walter Benjamin aproxima o romance da epopeia, já que ambos se baseiam na memória. Benjamin 
destaca a musa dos autores gregos, Mnemosina, aquela que se recorda e "leva o observador a um cerne histórico de linhas mestras”. ${ }^{15}$ No caso do romance, a estruturação se dá através do desencadeamento de um conjunto de histórias interligadas, existindo em cada uma delas uma Scherazade incumbida de lembrar-se. "É, em outras palavras, a lembrança que, como elemento artístico, filia-se no romance à memória, o elemento correspondente na narrativa, depois de a unidade de sua origem ter-se perdido na recordação, quando da decadência do poema épico.”16

Este estudo adota a perspectiva de Benjamin, incluindo assim o romance no gênero épico. A análise de Auster proposta aqui explora o diálogo com a obra de Bunyan, que pode ser considerada precursora do romance a partir da análise do teórico alemão Wolfgang Iser, em The implied reader. A estrutura formal da alegoria de Bunyan apresenta ora características que são próprias da epopeia, ora características que são próprias do romance, demonstrando o desligamento com a tradição da epos e o início do que hoje é conhecido como romance.

Em The implied reader, há uma coleção de ensaios que, a partir do ponto de vista da estética da recepção, analisa a evolução do romance de Bunyan a Beckett. Iser considera a obra de Bunyan como precursora do romance tanto devido a suas características formais, como também devido à trabalhada construção dos personagens alegóricos. ${ }^{17}$

Segundo a análise de Iser, o trajeto narrativo em O peregrino apresenta uma estrutura pouco convencional, especialmente para o século 17, de forma que o livro pode ser considerado um dos precursores do romance moderno. Iser trabalha a partir de dois eixos. O primeiro está relacionado com a leitura de Schöffler, que concebe O peregrino como uma antecipação dos primeiros romances de autores protestantes surgidos no século 18, como Robinson Crusoé, de Defoe. O segundo leva em consideração os argumentos de Tillyard, que incluem Bunyan na tradição da épica.

Iser observa que ambas as linhas de raciocínio têm fundamento, mas não isoladamente, já que o texto de Bunyan oscila continuamente entre a épica e o romance através de dois ângulos diferentes de visão: aquele que aponta para a ideia abstrata da busca da salvação e aquele que se dirige para o indivíduo, sua alma e o seu ser interior. Esse movimento está presente em todas as peças que montam o texto de Bunyan. Iser observa que, como na épica, os personagens apresentam nomes e funções alegóricas: Cristão, Boa

${ }^{15}$ BENJAMIN. O narrador, p. 73.

${ }^{16}$ BENJAMIN. O narrador, p. 73, grifo do autor.

ISER. The implied reader. Patterns of communication in prose fiction from Bunyan to Beckett, p. 128. 
Vontade, Evangelista, Sábio-Segundo-o-Mundo e Adulador, entre outros. Contraditoriamente, no entanto, eles também dão a impressão de serem feitos de carne e osso, destacando assim sua humanidade e individualidade, característica dos romances.

Esse movimento também é ressaltado na técnica da narrativa. O narrador onisciente descreve um sonho com um final previsível: a salvação do personagem principal, Cristão, e sua chegada à Cidade Celestial. A onisciência do narrador remete à épica. Em contraposição, Cristão percebe somente aquilo que lhe é imediato e que está diante de seu campo de visão. Como personagem, ele se desenvolve através do diálogo e de suas experiências pessoais, sendo levado pela tensão que surge a partir de sua incerteza com relação a seu futuro. Essa característica remete ao romance.

Iser continua sua análise nesse mesmo sentido, destacando o uso da prosa, através de diálogos de caráter argumentativo, que remetem ao indivíduo e à sua busca espiritual. Esses diálogos teriam a função de aumentar a consciência do personagem a respeito de sua própria situação e experiência, sempre trazendo algum ensinamento em consequência. Há também o uso do verso, que oferece ao leitor uma espécie de síntese ou critério geral a respeito da conduta do peregrino puritano. O uso da prosa aponta para a estrutura do romance, enquanto o verso, indicando um contexto mais geral, aponta para a estrutura da épica.

No decorrer do estudo de Iser, nota-se maior ênfase em características pertencentes ao romance, mais especificamente aquelas que se relacionam com o crescimento pessoal dos personagens principais: Cristão, Fiel e Esperança. Iser afirma que eles são mais do que personificações de uma ideia, já que superam suas características alegóricas, produzindo a edificação no sentido puritano. Esses personagens não se apresentam como peregrinos exemplares, mas como seres humanos, que, como tais, são fracos e falhos. Assim, pode-se afirmar que o texto de Bunyan se aproxima do romance e se afasta da épica.

Seguindo uma linha cronológica na história da literatura, e em consonância com Benjamin, considera-se O engenhoso fidalgo Dom Quixote de La Mancha como o "primeiro modelo perfeito do romance.” ${ }^{18} \mathrm{O}$ texto de Cervantes é conhecido como uma paródia das novelas de cavalaria, que, apesar de terem sido muito populares durante o período medieval, já estavam em declínio no início do século 17.

Com o passar do tempo, entretanto, outros sentidos afloraram desse romance tão rico e importante para a literatura ocidental. Dom Quixote, o protagonista louco do romance, passa a ser visto como um herói, prefigurando um indivíduo sonhador e idealista. Assim, todos os

\footnotetext{
${ }^{18}$ BENJAMIN. Origem do drama barroco alemão, p. 74.
} 
seus disparates podem ser bem fundamentados em uma retórica invertida entre o real e o imaginário, de forma semelhante a uma alegoria.

A imagem alegórica dos moinhos de vento é provavelmente a mais forte de todo o romance. Nessa cena Dom Quixote pensa estar diante de gigantes, enquanto Sancho Pança afirma e reafirma que são apenas moinhos de vento. O olhar de Dom Quixote assustado com uma possível ameaça ou um perigo se justifica através de uma retórica alegórica relacionada ao contexto histórico de Cervantes. De forma semelhante à paródia de Hawthorne, que relaciona o trem com o progresso industrial, os moinhos são uma espécie de motor movido a energia eólica e representam as grandes engenhocas produzidas pelo homem devido à especialização do conhecimento na área da mecânica.

De fato, o olhar de Dom Quixote está mais próximo do imaginário medieval das cavalarias, mas seu olhar se movimenta também para o presente histórico dos moinhos de vento, simultaneamente como algo que ameaça e fascina por sua grandeza e especialização. Percebe-se, assim, que a obra de Cervantes possui características estruturais, formais e retóricas que indicam uma nova direção também na área da literatura. Há a negação da tradição anterior através da ridicularização e a indicação de uma nova retórica, irônica e desconexa. Pode-se sugerir, então, que, através do uso de figuras alegóricas associadas a um discurso irônico, Dom Quixote seria o primeiro exemplo de um romance alegórico.

É importante ressaltar que até o Renascimento a ironia era simplesmente um recurso retórico, sendo considerada como um dentre os vários modos de dizer uma coisa e significar outra, e, portanto, como uma forma de alegoria. Entretanto, devido à ruptura com a analogia da linguagem alegórica e à entrada da subjetividade na história, a partir do Romantismo a ironia se torna uma atitude para com a própria existência. Já não há divindades que revelam segredos, há apenas o homem diante de um mundo escasso de significado.

O romance na contemporaneidade segue a mesma trilha, de forma que não usa enredos tradicionais, mas inventados ou baseados em incidentes reais. Além disso, há a ausência das convenções formais. Lukács, em A teoria do romance, afirma que o mundo criado por Dante, em seu poema épico, expressa uma totalidade estrutural, através de um sistema que sugere a substancialidade dos conceitos trabalhados. Já o romance atinge sua totalidade com a sistematização de conceitos abstratos. 
No entanto, a realidade criada no romance traz à tona apenas "the distance separating the systematization from concrete life”. ${ }^{19}$ Lukács dá ênfase aos seguintes pontos: personagens nostálgicos por uma perfeição utópica, que é percebida como verdade última; a existência de estruturas sociais que se baseiam unicamente em sua presença factual e na simples habilidade de continuar existindo; e, finalmente, a intenção estética de dar forma ao romance, que, ao invés de conciliar a interioridade do mundo subjetivo ao convencionalismo do mundo objetivo, faz com que subsista a distância entre os dois. A totalidade do romance não se resolve, deixando transparecer, assim, uma dissonância metafísica. ${ }^{20}$

De acordo com Lukács, a confirmação da existência de uma dissonância precede o ato estético de dar forma e está presente em todos os gêneros. Entretanto, no caso do romance, a dissonância não é precedente, e sim, sua própria forma. Lukács conclui que a intenção ética no romance deixa de ser uma precondição puramente formal, passando a ser "visible in the creation of every detail and hence is, in its most concrete content, an effective structural element of the work itself”. ${ }^{21}$ Em contraposição aos demais gêneros literários que comportam uma forma completa, o romance se revela inacabado, dando a impressão de estar sempre no processo de vir a ser.

Além disso, segundo Lukács, a totalidade objetiva esperada pela épica se quebra no romance, que dá forma somente a aspectos subjetivos dessa totalidade. É importante ressaltar que a subjetividade, mesmo que altamente consciente de si mesma, se torna cada vez mais abstrata. Assim surge a ironia, simultaneamente como o autorreconhecimento e a autonegação dessa subjetividade. Lukács afirma que a ironia seria uma espécie de autocorreção da fragilidade do mundo, deixando transparecer ambiguidades que demonstram as várias interpretações de uma mesma questão, ou as fissuras presentes em afirmações categóricas. ${ }^{22}$

O estudo de Lukács fornece a base para uma compreensão do romance na Modernidade. Apesar disso, não menciona a possível relação que o romance teria com a alegoria. Levando em consideração a obra de Auster, é relevante focalizar a atenção em seus personagens nostálgicos por uma realidade diferente, em que não há inimizades, violência,

LUKÁCS. The theory of the novel: a historico-philosopical essay on the forms of great epic literature p. 70.

LUKÁCS. The theory of the novel: a historico-philosopical essay on the forms of great epic literature, p. 70 e 71.

${ }^{21}$ LUKÁCS. The theory of the novel: a historico-philosopical essay on the forms of great epic literature p. 70.

LUKÁCS. The theory of the novel: a historico-philosopical essay on the forms of great epic literature, p. 74 e 75. 
usurpação e mentira. A amizade e o cuidado com o próximo surgem em tentativas pontuais de alguns personagens que procuram uma fuga da realidade cruel. Entretanto, as estruturas sociais que alicerçam o país das últimas coisas persistem em sua existência incoerente e subversiva. Assim, o romance de Auster aponta justamente para a dissonância metafísica mencionada por Lukács, pois gira em torno de questões que não se solucionam. Seguindo a mesma lógica, a narrativa em si é inacabada, sugerindo sempre um processo de vir a ser.

A alegoria contemporânea e o romance se unem exatamente nesse ponto. Ambos são construídos a partir de fragmentos de uma história em ruínas, gerando no leitor a sensação de incompletude, de transitoriedade e de necessidade de decifração. No caso de Auster, seus personagens alegóricos apresentam nomes, características físicas e pessoais que podem ser relacionados a pessoas ou eventos históricos. Entretanto, ao contrário da alegoria caricatural usada por Dante, Bunyan e até mesmo por Hawthorne, seus personagens são retratados a partir de uma perspectiva extremamente realista. Sugere-se que Auster dá continuidade ao tipo de alegoria usada por Cervantes, que, apesar de seu alto grau de ironia, remete a pessoas reais que vivem em um mundo semelhante ao do leitor. Afirma-se, então, que a narrativa de Auster apresenta características comuns a ambos os gêneros textuais, de forma que possa ser considerada um romance alegórico.

\section{CONCLUSÃO}

Assim é a epígrafe de No país das últimas coisas: "Não há muito tempo atrás, passando pelo portão dos sonhos, visitei aquela região da terra em que fica a famosa Cidade da Destruição.”³ A paródia de Hawthorne começa com as mesmas palavras. A alegoria de Bunyan também faz referência a um sonho, mas não se inicia com uma visita à Cidade da Destruição, e sim com a fuga dela. Esses movimentos simbolizam o foco dos protagonistas: uma aventura de busca, uma viagem turística, uma peregrinação espiritual. Enquanto os dois primeiros se relacionam com o contexto histórico, cultural e econômico a partir do século 19 até a Modernidade, a última obra está focada em questionamentos teológicos do século 17.

A leitura das três obras analisadas traz à tona o uso da alegoria como recurso linguístico e como gênero literário em períodos distintos. Através desse trajeto, pode-se afirmar que a figura de linguagem se relaciona com o surgimento do romance, dando origem também a narrativas alegóricas com traços de ironia, como é o caso de Dom Quixote. Além

\footnotetext{
"Not a great while ago, passing through the gate of dreams, I visited that region of the earth in which lies the famous City of Destruction." (Hawthorne, citado na epígrafe de In the country of last things, 1988.)
} 
disso, percebe-se como a história do cristianismo e suas manifestações na literatura permearam e influenciaram a alegoria e sua forma de interpretação. Em uma linha cronológica, o industrialismo e a vinda da modernidade também trouxeram reconfigurações para esse recurso linguístico.

Apesar de $O$ peregrino ser uma alegoria cristã que se aproxima dos moldes da Divina Comédia, já apresenta características que podem ser identificadas, posteriormente, no gênero do romance. O conto de Nathaniel Hawthorne, “A estrada de ferro celestial”, é uma paródia da alegoria de Bunyan, e, portanto, além de criticar a tradição da analogia através de suas caricaturas alegóricas, pode ser visto como a semente da alegoria moderna presente na narrativa de Auster.

A partir de tal análise e dos estudos de Walter Benjamin, propõe-se uma configuração contemporânea da alegoria, seguindo um padrão semelhante ao da alegoria do Período Barroco. A compreensão de tal reconfiguração permite a análise do texto de Auster e, a partir daí, a percepção de sua dupla tendência textual, apontando tanto para o romance como para a alegoria. Isso sugere a possibilidade de classificá-lo como um romance alegórico.

\begin{abstract}
This study investigates the allegoric character of the contemporary novel In the country of last things, and its intertextuality with the parody "The celestial railroad" and the allegory The pilgrim's progress. From this reading, the relations between allegory and the rise of the novel are analyzed.
\end{abstract}

\title{
KEYWORDS
}

Literature in English, allegory, novel, Walter Benjamin, contemporary literature

\section{REFERÊNCIAS}

AUSTER, Paul. In the country of last things. Nova York: Penguin Books, 1988.

BENJAMIN, Walter. Origem do drama barroco alemão. Trad. Sérgio Paulo Rouanet. São Paulo: Brasiliense, 1984.

BENJAMIN, Walter. O narrador. In: . et al. Textos escolhidos. Seleção de Zeljko Loparic e Otília B. Fiori. São Paulo: Abril Cultural, 1975. p. 63-81. (Coleção Os Pensadores) 
BUNYAN, John. O peregrino. Trad. Eduardo Pereira e Ferreira. São Paulo: Mundo Cristão, 2006.

BUNYAN, John; OWENS, W. R. The pilgrim's progress. Oxford: Oxford University Press, 2003.

CERVANTES, Miguel de. Dom Quixote. Livro primeiro. Trad. Viscondes de Castilho e Azevedo. Porto Alegre: L\&PM, 2007.

CERVANTES, Miguel de. Dom Quixote. Livro segundo. Trad. Viscondes de Castilho e Azevedo. Porto Alegre: L\&PM, 2007.

DE MAN, Paul. Alegorias da leitura: linguagem figurativa em Rousseau, Nietzsche, Rilke e Proust. Trad. Lenita R. Esteves. Rio de Janeiro: Imago Editora, 1996.

HANSEN, João Adolfo. Alegoria: construção e interpretação da metáfora. São Paulo: Editora Unicamp, 2006.

HAWTHORNE, Nathaniel. Histórias de Nathaniel Hawthorne. Sel. e trad. de O. Kraehenbuel. São Paulo: Cultrix, 1964.

HAWTORNE, Nathaniel. The celestial railroad, 1843. Disponível em <http://www.walkworthy.net>. Acesso em: 15 de maio 2009.

HOLLOWAY, Julia Bolton. The pilgrim and the book: a study of Dante, Langland, and Chaucer. Nova York: Peter Lang, 1992.

ISER, Wolfgang. The implied reader. Patterns of communication in prose fiction from Bunyan to Beckett. London: The Jonhs Hopkins University Press, 1974.

LOPES, Augustus Nicodemos. A bíblia e seus intérpretes: uma breve história da interpretação. São Paulo: Cultura Cristã, 2007.

LUKÁCS, Georg. The theory of the novel: a historico-philosopical essay on the forms of great epic literature. Trad. Anna Bostock. Massachusetts: The MIT Press, 1971.

SHARROCK, Roger. Introduction. In: BUNYAN, John. The pilgrim's progress. 5. ed. Harmondsworth: Penguin Books, 1965. p. 7-26.

WATT, Ian. A ascensão do romance: estudos sobre Defoe, Richardson e Fielding. Trad. Hildegard Feist. São Paulo: Editora Schwarcz Ltda, 1996.

WEINSTEIN, Cindy. The literature of labor and the labors of literature: allegory in nineteenth-century American fiction. Cambridge, UK: University Press, 1995. 